\title{
PRODUÇÃO DE ALFACE UTILIZANDO-SE HÚMUS E DOSES DE ADUBO MINERAL ACONDICIONADOS EM GARRAFA PET
}

\author{
Eduardo Henrique Lima Mazzuchelli ${ }^{1}$; Rita de Cássia Lima Mazzuchelli ${ }^{2}$; Pedro Veridiano Baldotto ${ }^{3}$ \\ Universidade do Oeste Paulista - UNOESTE, Programa de Pós-Graduação em Agronomia, Curso de Graduação em \\ Agronomia, Presidente Prudente -SP. E-mail: eduardomazzuchelli@yahoo.com.br
}

\section{RESUMO}

O objetivo do presente trabalho foi avaliar a adição de húmus de minhoca em proporções com solo e adubação mineral para a produção de alface em reutilização de garrafas pet. O experimento foi conduzido em casa de vegetação localizada no Campus II da Universidade do Oeste Paulista (UNOESTE), no mês de maio de 2014. Para o desenvolvimento do experimento foram utilizadas cinquenta garrafas pet com capacidade para 2 L, cada garrafa representou uma parcela experimental, foram conduzidos os seguintes tratamentos: T1- 100\% de húmus; T2- Mistura 1:1 terra de barranco e húmus; T3- Mistura 1:1 terra de barranco e húmus + 0,33 g de adubo mineral (04-14-08); T4- Mistura 1:1 terra de barranco e húmus + 1 g de adubo mineral (04-14-08); T5Mistura 1:1 terra de barranco e húmus $+3 \mathrm{~g}$ de adubo mineral (04-14-08). Cada tratamento foi conduzido com dez repetições. Cada garrafa pet recebeu uma muda de alface var."Vanda" com cerca de 7 dias após a semeadura, que foram obtidas de viveiro comercial. Após 30 dias do cultivo nas garrafas pet, as plantas de alface foram avaliadas quanto ao: número de folhas; altura de mudas; comprimento de raiz; massa fresca de parte aérea; massa fresca de sistema radicular. As variáveis analisadas para a alface em cada tratamento foram submetidos ao SISVAR, e utilizou-se o teste de Tukey para comparação das médias. A produção de alface em garrafas pet utilizando o húmus de minhoca como substrato apresentou o melhor desempenho, promovendo maior desenvolvimento das plantas.

Palavras-chave: Lactuca sativa L.; nutrição de plantas; reutilização de materiais.

\section{LETTUCE PRODUCTION USING HUMUS AND MINERAL FERTILIZER PACKED ON PLASTIC BOTTLES}

\begin{abstract}
The objective of this study was to evaluate the addition of earthworm castings in proportions with soil and mineral fertilizer for lettuce production in reusing plastic bottles. The experiment was conducted in a greenhouse located in the Campus II of the University of Oeste Paulista (UNOESTE), in May 2014 for the development of the experiment fifty plastic bottles were used for up to $2 \mathrm{~L}$, each bottle represented one experimental plot the following treatments: T1 100\% of humus; T2-1: 1 Mixture steep bank and humus; T3 Mixture 1: 1 steep bank and humus $+0.33 \mathrm{~g}$ of mineral fertilizer (04-14-08); T4-1: 1 Mixture steep bank and humus $+1 \mathrm{~g}$ of mineral fertilizer (04-14-08); T5- Mixture 1: 1 steep bank and humus $+3 \mathrm{~g}$ of mineral fertilizer (04-14-08). Each treatment was conducted with ten repetitions. Pet bottle each received a change of lettuce var. "Vanda" about 7 days after sowing, which were obtained from commercial nursery. After 30 days of cultivation in plastic bottles, the lettuce plants were evaluated for number of leaves; height of seedlings; root length; fresh weight of shoots; fresh weight of the root system. The variables analyzed for lettuce in each treatment were subjected to SISVAR, and used the Tukey test for comparison of means. The lettuce production in pet bottles using worm castings as a substrate showed the best performance, promoting major development.
\end{abstract}

Keywords: Lactuca sativa L .; plant nutrition; reuse of materials. 


\section{INTRODUÇÃO}

A alface (Lactuca sativa L.) é uma planta herbácea com centro de origem no sul da Europa e na Ásia Ocidental. Pertencente à família Asteraceae é uma das culturas mais comuns na mesa do consumidor final e, dentre as mais consumidas estão às variedades crespa e americana.

Devido ao fato de ser uma cultura com boa aceitação pelo consumidor final, a alface durante o passar do tempo teve que se adaptar ao ciclo produtivo, foram então desenvolvidos cultivares que se adaptam as condições de campo durante o ano todo, já que a cultura inicialmente era cultivada apenas no período outono-inverno.

A melhoria das técnicas de cultivo permite ao produtor de hortaliças maximizarem seus lucros e facilitar todo o processo produtivo, com o objetivo de aumentar a produção, a qualidade do produto e principalmente os lucros da atividade.

A realização de hortas em pequenos espaços passa a ser uma medida que o consumidor quer adotar para produzir seu próprio alimento de forma saudável e livre de defensivos químicos, consequentemente buscar tecnologias que permitem a produção em pequenos espaços torna-se necessário para obter o sucesso na produção de hortaliças.

A reutilização de embalagens que são destinadas ao descarte é de grande importância, pois reduz a produção de lixo, e possibilita seu uso para outros fins, como por exemplo, a produção de hortaliças.

O plantio de hortaliças em garrafas pet pode favorecer o consumidor há consumir produtos com maior qualidade, portanto, buscar melhorar o substrato para a formação de hortaliças em espaços reduzidos passa a ser uma necessidade para alcançar êxito em sua produção.

O objetivo do presente trabalho foi avaliar a adição de húmus de minhoca em proporções com solo e adubo para a produção de alface em reutilização de garrafas pet.

\section{METODOLOGIA}

O experimento foi conduzido em casa de vegetação localizada no Campus II da Universidade do Oeste Paulista (UNOESTE) - Faculdade de Ciências Agrárias, em Presidente Prudente - SP, no mês de maio de 2014..

O clima da região é pela classificação de Köppen Aw como mesotérmico com verões quentes e período chuvoso bem definido nos meses de setembro a março e invernos secos com temperaturas mais amenas nos meses de abril a setembro. 
Para o desenvolvimento do experimento foram utilizadas cinquenta garrafas pet com capacidade para 2 L, cada garrafa representou uma parcela experimental, foram conduzidos os seguintes tratamentos:

T1- 100\% de húmus;

T2- Mistura 1:1 terra de barranco e húmus;

T3- Mistura 1:1 terra de barranco e húmus + 0,33 g de adubo mineral (04-14-08);

T4- Mistura 1:1 terra de barranco e húmus +1 g de adubo mineral (04-14-08);

T5- Mistura 1:1 terra de barranco e húmus + 3 g de adubo mineral (04-14-08).

Cada garrafa pet recebeu uma muda de alface var."Vanda" com cerca de 7 dias após a semeadura, que foram obtidas de viveiro comercial. As mudas receberam irrigação periódica, sendo três vezes ao dia, por aspersão instalada no viveiro.

Após 30 dias do cultivo nas garrafas pet, as plantas de alface foram avaliadas quanto ao:

a) Número de folhas (maiores que $1 \mathrm{~cm}$ )

b) Altura de mudas (cm)

c) Comprimento de raiz $(\mathrm{cm})$.

d) Massa fresca de parte aérea (g)

e) Massa fresca de sistema radicular (g).

As variáveis analisadas para a alface em cada tratamento foram submetidos ao programa estatístico SISVAR, e utilizou-se o teste de Tukey a 1 e 5\% de probabilidade para comparação das médias.

\section{RESULTADOS}

Para a variável comprimento de parte aérea, podemos acompanhar na tabela 1 , que o tratamento húmus apresentou maior média para o comprimento de plantas, havendo diferença significativa entre os tratamentos empregados, com plantas de aproximadamente $19,73 \mathrm{~cm}$ de comprimento. Em seguida, está o tratamento com húmus e terra, com 18,08 cm, que não difere significativamente do tratamento húmus, e húmus com terra e adubo nas doses de $1 \mathrm{~g}$ e $3 \mathrm{~g}$.

Na tabela 1 é possível visualizarmos ainda que os tratamentos com húmus + terra e adubo mineral em 1g e $3 g$ apresentam a mesma média de $17,10 \mathrm{~cm}$, e não diferem significativamente dos tratamentos húmus com terra e húmus com terra e adubo em $0,33 g$, que apresentou a pior média, de $15,36 \mathrm{~cm}$. 
Tabela 1. Comprimento da parte aérea (C.P.A.) em centímetros da alface cultivada em garrafas pet, com combinações de húmus com terra e adições de adubos.

\begin{tabular}{ll}
\hline Tratamentos & C.P.A.(cm) \\
\hline Húmus com terra & $18,08 \mathrm{ab}$ \\
Húmus & $19,73 \mathrm{a}$ \\
Húmus com terra e 0,33 g de NPK & $15,36 \mathrm{c}$ \\
Húmus com terra e 1,00 g de NPK & $17,10 \mathrm{bc}$ \\
Húmus com terra e 3,00 g de NPK & $17,10 \mathrm{bc}$ \\
\hline $\mathrm{F}$ & $6,95^{* *}$ \\
\hline C.V. (\%) & $10,96^{* *}$ \\
\hline
\end{tabular}

**Médias seguidas de mesma letra não diferem estatisticamente pelo teste Tukey (1\%).

O comprimento de raízes foi influenciado de acordo com os manejos empregados. tratamento húmus com terra e $3 \mathrm{~g}$ de adubo proporcionou o maior incremento de crescimento radicular, com raízes de aproximadamente $30,57 \mathrm{~cm}$ de comprimento, diferindo significativamente dos demais tratamentos.

O menor comprimento de raízes foi obtido com o tratamento de húmus com terra e a adição de 0,33 gramas de adubo (Tabela 2).

Tabela 2. Comprimento do sistema radicular (C.S.R.) em centímetros da alface cultivada em garrafas pet, com combinações de húmus com terra e adições de adubos.

\begin{tabular}{ll}
\hline Tratamentos & C.S.R. \\
\hline Húmus com terra & $23,19 \mathrm{ab}$ \\
Húmus & $24,27 \mathrm{ab}$ \\
Húmus com terra e 0,33 g de NPK & $22,46 \mathrm{~b}$ \\
Húmus com terra e 1,00 g de NPK & $25,10 \mathrm{ab}$ \\
Húmus com terra e 3,00 g de NPK & $30,57 \mathrm{a}$ \\
\hline F & $3,04^{*}$ \\
\hline C.V. (\%) & 23,17 \\
\hline
\end{tabular}

*Médias seguidas de mesma letra não diferem estatisticamente pelo teste Tukey (5\%).

A massa fresca da parte aérea foi superior com a realização do tratamento de húmus, este tratamento foi superior aos demais conduzidos, sendo que o tratamento de húmus com terra e a adição de 0,33 gramas de adubo foi o que apresentou menor desenvolvimento da parte aérea da alface (Tabela 3). 
Tabela 3. Massa fresca da parte aérea (M.F.P.A.) em gramas da alface cultivada em garrafas pet, com combinações de húmus com terra e adições de adubos.

\begin{tabular}{ll}
\hline Tratamentos & M.F.P.A. \\
\hline Húmus com terra & $37,60 \mathrm{ab}$ \\
Húmus & $39,79 \mathrm{a}$ \\
Húmus com terra e 0,33 g de NPK & $19,48 \mathrm{c}$ \\
Húmus com terra e 1,00 g de NPK & $28,59 \mathrm{bc}$ \\
Húmus com terra e 3,00 g de NPK & $32,80 \mathrm{ab}$ \\
\hline F & $8,40 * *$ \\
\hline C.V. (\%) & 27,82 \\
\hline ** Médias seguidas de mesma letra não diferem estatisticamente pelo teste Tukey (1\%).
\end{tabular}

A massa fresca do sistema radicular da alface foi superior com a realização do tratamento de húmus, este tratamento foi superior aos demais conduzidos, sendo que o tratamento de húmus com terra e a adição de 0,33 gramas de adubo foi o que apresentou menor desenvolvimento da parte aérea da alface (Tabela 4).

Tabela 4. Massa fresca do sistema radicular (M.F.S.R.) em gramas da alface cultivada em garrafas pet, com combinações de húmus com terra e adições de adubos.

\begin{tabular}{ll}
\hline Tratamentos & M.F.S.R. \\
\hline Húmus com terra & $3,15 \mathrm{c}$ \\
Húmus & $5,57 \mathrm{a}$ \\
Húmus com terra e 0,33 g de NPK & $3,15 \mathrm{c}$ \\
Húmus com terra e 1,00 g de NPK & $3,90 \mathrm{bc}$ \\
Húmus com terra e 3,00 g de NPK & $5,40 \mathrm{ab}$ \\
\hline F & $9,75^{* *}$ \\
\hline C.V. (\%) & 28,32 \\
\hline$* *$ Médias seguidas de mesma letra não diferem estatisticamente pelo teste Tukey (1\%).
\end{tabular}

O número de folhas foi maior no tratamento com a mistura de húmus e terra e adição de 3,00 gramas de adubo. Sendo que a mistura de terra com húmus e aplicação de 0,33 gramas de adubo mineral proporcionou os menores valores de números de folhas (Tabela 5).

Tabela 5. Número de folhas (N.F.) da alface cultivado em garrafas pet, com combinações de húmus com terra e adições de adubos. 


\begin{tabular}{ll}
\hline Tratamentos & N.F. \\
\hline Húmus com terra & $12,20 \mathrm{ab}$ \\
Húmus & $12,10 \mathrm{ab}$ \\
Húmus com terra e 0,33 g de NPK & $10,00 \mathrm{~b}$ \\
Húmus com terra e 1,00 g de NPK & $11,30 \mathrm{ab}$ \\
Húmus com terra e 3,00 g de NPK & $12,60 \mathrm{a}$ \\
\hline F & $3,08^{*}$ \\
\hline C.V. (\%) & 15,94 \\
\hline *Médias seguidas de mesma letra não diferem estatisticamente pelo teste Tukey (5\%).
\end{tabular}

*Médias seguidas de mesma letra não diferem estatisticamente pelo teste Tukey (5\%).

\section{DISCUSSÃO}

De acordo com Souza et al. (2014) a utilização de húmus como substrato húmus enriquecido com $5 \%$ de cama de aviário promoveu um maior comprimento de parte aérea e um maior peso seco de parte área e de raiz, quando comparado ao substrato comercial Plantmax ${ }^{\circledR}$ no cultivo de tomate.

Oliveira et al. (2001) constataram que a dose de $41,0 \mathrm{t} \mathrm{ha}^{-1}$ de esterco bovino promoveu máximo peso médio (900 g) e máxima produtividade $\left(47,0 \mathrm{t} \mathrm{ha}^{-1}\right)$ de cabeças, enquanto as doses de 27,0 e $29,0 \mathrm{t} \mathrm{ha}^{-1}$ de húmus de minhoca foram responsáveis pelo peso médio máximo (700 g) e máxima produtividade $\left(38,0 \mathrm{t} \mathrm{ha}^{-1}\right)$, respectivamente de repolho híbrido.

Oliveira e Santos (2009), estudando compostos alternativos, como lixo caseiro, restos de cultura, esterco bovino e húmus, e misturas destes materiais, observaram que a utilização de vermicompostos de minhoca apresentou-se como mais eficiente para a produção de hortaliças, obtendo valores satisfatórios de pH, S e CTC, constituindo fontes alternativas de matéria orgânica para o solo e de nutrientes para as plantas.

\section{CONCLUSÃO}

A produção de alface em garrafas pet utilizando o húmus de minhoca como substrato torna-se eficiente, promovendo maiores desenvolvimentos das plantas.

\section{REFERÊNCIAS}

BAUMGARTNER, D.; SAMPAIO, S. C.; SILVA, T. R. D.; TEO, C. R.; VILAS BOAS, M. A. Reúso de águas residuárias da piscicultura e da suinocultura na irrigação da cultura da alface. Engenharia Agrícola, v. 27, 2007.

FERREIRA, D.F. SISVAR: um programa para análises e ensino de estatística. In: Revista Symposium. p. 36-41. 2008.

FILGUEIRA, F.A.R. Novo manual de Olericultura: agrotecnologia moderna na produção e comercialização de hortaliças. Viçosa - MG. 3ํEd. Editora: UFV, 421 p. 2008. 
LIMA, G. K. L.; LIBERALINO FILHO, J.; LINHARES, P. C. F.; MARACAJÁ, P. B.; ANDRADE, W.G. Produção de mudas de alface com composto orgânico misto de três texturas em três tipos de bandejas. Revista Caatinga, (Mossoró,Brasil), v.20, n.3, p.160-166, julho/setembro. 2007a.

LIMA, R. C. M.; STAMFORD, N. P.; SANTOS, E. R. S.; DIAS, S. H. L. Rendimento da alface e atributos químicos de um Latossolo em função da aplicação de biofertilizantes de rochas com fósforo e potássio. Horticultura Brasileira 25: 224-229. 2007b. http://dx.doi.org/10.1590/S0102$\underline{05362007000200019}$

LIMA, K.D.S.; OLIVEIRA, F.D.A.D.; PORDEUS, R.V.; SANTOS, C.F.D.; LIMA, C.J.G.D.S. Acúmulo e partição de massa seca em alface cultivada em diferentes substratos. Revista Verde de Agroecologia e Desenvolvimento Sustentável, 6(4). v.6, n.4, p. 34 - 40. 2011.

LIMA, M.E.; CARVALHO, D.F.; SOUZA, A.P.; GUERRA, J.G.M.; RIBEIRO, R.L.D. Desempenho da alface em cultivo orgânico com e sem cobertura morta e diferentes lâminas d'água. Ciência e agrotecnologia. [online]. vol.33, n.6, pp. 1503-1510. 2009.

MINAMI, K. Produção de mudas de alta qualidade. Piracicaba, SP: ESALQ, 2010. 426 p.

OHSE, S.; DOURADO-NETO, D.; MANFRON, P.A.; SANTOS, O.S. Qualidade de cultivares de alface produzidos em hidroponia. Scientia Agricola, v.58, n.1, p.181-185, jan./mar. 2001a.

OHSE, S.; NOGUEIRA FILHO, H.; MANFRON, P.A.; DOURADO-NETO, D. Composição centesimal e teores de vitamina $C$, cálcio e fósforo de seis cultivares de alface produzidas sob dois sistemas de cultivo. INSULA Revista de Botânica, 30, 47. 2001b. http://dx.doi.org/10.1590/S0103$\underline{90162001000100027}$

OLIVEIRA, A.P.; ESPÍNOLA, F.E.J.; ARAÚJO, J.S.; COSTA, C.C. Produção de raízes de cenoura cultivadas com húmus de minhoca e adubo mineral. Horticultura Brasileira, Brasília, v. 19, n. 1, p. 77 - 80, março 2001.

OLIVEIRA, E. M.; SANTOS, M. J. Influência das minhocas sobre as características químicas de composto, vermicomposto e solo. Engenharia Ambiental - Espírito Santo do Pinhal, v. 6, n. 1, p. 074-081, jan/abr 2009

OLIVEIRA, N. G.; DE-POLLI, H; ALMEIDA, D. L.; GUERRA, J. G. M. Plantio direto de alface adubada com "cama" de aviário sobre coberturas vivas de grama e amendoim forrageiro. Horticultura Brasileira 24: 112-117. 2006. http://dx.doi.org/10.1590/S0102-05362006000100023

PORTO, M. L.; ALVES, J. C.; SOUZA, A. P.; ARAUJO, R. C.; ARRUDA, J. A. Nitrate production and accumulation in lettuce as affected by mineral Nitrogen supply and organic fertilization. Horticultura Brasileira 26: 227-230. 2008. http://dx.doi.org/10.1590/S0102-05362008000200019

RESENDE, G.M.; YURI, J.E.; MOTA, J.H.; SOUZA, R.J.; FREITAS, S.A.C.; RODRIGUES JUNIOR, J.C. Efeitos de tipos de bandejas e idade de transplantio de mudas sobre o desenvolvimento e produtividade de alface americana. Horticultura Brasileira, Brasília, v. 21, n. 3, p. 558-563, julhosetembro 2003. http://dx.doi.org/10.1590/S0102-05362003000300029 
SALA, F.C.; COSTA, C.P. 'Piraroxa': Cultivar de alface crespa de cor vermelha intensa. Horticultura Brasileira, Brasília, v.23, n.1, p.158-159, jan.-mar. 2005. http://dx.doi.org/10.1590/s0102$\underline{05362005000100033}$

SANTOS, R. H. S.; SILVA, F. D.; CASALI, V. W. D.; CONDE, A. R. Efeito residual da adubação com composto orgânico sobre o crescimento e produção de alface. Pesquisa Agropecuária Brasileira, v. 36, n. 11, p. 1395-1398, 2001. http://dx.doi.org/10.1590/S0100-204X2001001100010

SOUZA, J. M. P. F.; LEAL, M. A.; ARAÚJO, M. L. Produção de mudas de tomateiro utilizando húmus de minhoca e cama de aviário como substrato e o biofertilizante Agrobio como adubação foliar. Seropédica-RJ: PESAGRO RIO.[Links], 2014.

VILAS BÔAS, R. L. V.; PASSOS, J. C.; FERNANDES, D. M.; BULL, L. T.; CEZAR, V. R. S.; GOTO, R. Efeito de doses e tipos de composto orgânicos na produção de alface em dois solos sob ambiente protegido. Horticultura Brasileira, v. 22, p. 28-34, 2004. http://dx.doi.org/10.1590/S0102$\underline{05362004000100006}$ 